\title{
Who is most likely to require a higher level of care: predicting risk of hospitalization
}

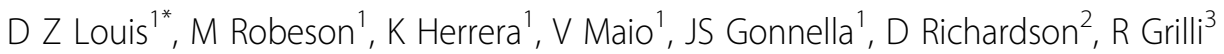 \\ From 26th Patient Classification Systems International (PCSI) Working Conference \\ Munich, Germany. 15-18 September 2010
}

\section{Introduction}

Health-care services are increasingly focused on care of individuals with chronic illness. Predicting those who are at greatest risk is critical in the design of case or disease management programs. The goal of this project is to develop models that can be used to identify people who are at high risk for hospitalization, and who would potentially benefit from participating in chronic disease management programs.

\section{Methods}

We developed a predictive model using the 2002-2007 Regione Emilia-Romagna longitudinal health-care administrative database, which includes linked demographic, hospital, outpatient pharmacy, and referral data for laboratory, $x$-ray and specialist physician visits for 3.3 million adult residents of the region. We defined the dependent variable as a "hospitalization (or death) for problems that are potentially avoidable in patients who have diseases or problems amenable to disease management." The independent variables included demographic variables, morbidity indicators, and quality-of-care indicators.

A boosted regression tree predictive model was developed using an enriched case-control training sample of 50,000 adults. Predictive performance and calibration of the model was assessed on an independent validation sample. Model discrimination was assessed using the $\mathrm{C}$-statistic, the area under the Receiver-Operator Characteristics curve. Calibration was assessed using a Hosmer-Lemeshow table of predicted versus observed proportions hospitalized, stratified by risk category.

'Thomas Jefferson University, Philadelphia, PA, USA

Full list of author information is available at the end of the article

\section{Results}

Model discrimination was good $(\mathrm{C}$-statistic $=0.82)$. The overall rate of hospitalization in Emilia-Romagna for the selected conditions was $6.0 \%$. We tabulated the actual (observed) and the predicted hospitalization rate within each category. Model calibration was excellent. For example, in the highest risk decile, $26 \%$ of the patients were hospitalized. The model predicted a hospitalization rate of $27 \%$ for this group.

We then applied the model to the entire adult population of the Emilia-Romagna region ( $\mathrm{n}=3.3$ million) to identify those residents with the highest predicted risk of hospitalization.

The population was divided into 4 groups based on predicted risk of hospitalization:

Very high risk: predicted risk of hospitalization is $\geq 50 \%$

High risk: predicted risk of hospitalization is $25-49 \%$

Moderate risk: predicted risk of hospitalization is $10-24 \%$

Low risk: predicted risk of hospitalization is $<10 \%$

162,140 residents of the region, or $4.9 \%$ of the population, were identified as high risk. Of these people, 34\% were hospitalized in the following year for one of the selected conditions and $12.8 \%$ died. Despite being less than $5 \%$ of the population, the high-risk group accounted for more than $30 \%$ of hospital expenditures for selected problems: $€ 440.1$ million.

In addition to patient age, the variables with the greatest relative influence on predicted risk of hospitalization included the number of chronic diseases, polypharmacy, and the presence of potentially inappropriate prescription drugs for elderly patients. Chronic diseases affecting the cardiovascular, gastrointestinal, musculoskeletal, respiratory and neurological systems were prevalent in high-risk patients, as were mental health problems. For those patients hospitalized in previous years, specific 
Table 1 Number of patients by predicted risk group, hospitalization, and cost

\begin{tabular}{|c|c|c|c|c|c|c|}
\hline \multirow[t]{2}{*}{ Risk of Hospitalization } & \multicolumn{2}{|c|}{ High Risk 25-49\% } & \multicolumn{2}{|c|}{ Very High Risk $50-100 \%$} & \multicolumn{2}{|l|}{ Total } \\
\hline & No. & $\%$ & No. & $\%$ & No. & $\%$ \\
\hline Total population & 162,140 & $4.9 \%$ & 1,385 & $0.0 \%$ & $3,333,943$ & $100 \%$ \\
\hline Hospitalized for selected conditions* & 55,833 & $34.4 \%$ & 815 & $58.8 \%$ & 201,590 & $6.0 \%$ \\
\hline Died from selected conditions & 20,678 & $12.8 \%$ & 453 & $32.7 \%$ & 42,306 & $1.3 \%$ \\
\hline Hospital costs for selected conditions * & \multicolumn{2}{|c|}{$€ 440,109,568$} & \multicolumn{2}{|c|}{$€ 6,713,382$} & \multicolumn{2}{|c|}{$€ 1,446,983,397$} \\
\hline$\%$ of hospital costs for selected conditions (row\%) & \multicolumn{2}{|c|}{$30.4 \%$} & \multicolumn{2}{|c|}{$0.5 \%$} & & \\
\hline
\end{tabular}

* Patients who were hospitalized for $>2$ days for selected conditions.

severity stages of certain chronic diseases (e.g., coronary artery disease, diabetes mellitus) were predictive of future risk. Table 1.

\section{Conclusions}

The longitudinal database available in the EmiliaRomagna region made it feasible to develop models that could identify individuals at high risk of future hospitalization. Of course, identifying those at risk is only one step in helping patients modify those risks. The EmiliaRomagna region includes 11 Local Health Authorities (LHA); each LHA is further organized into up to 6 health districts. Model results were prepared for each LHA and health district in order to assist the directors general and medical directors to identify residents at high risk. In addition, to assist them in their efforts to improve chronic care management, a review of the international literature was performed to identify chronic disease management programs that have shown promise.

\section{Author details}

${ }^{1}$ Thomas Jefferson University, Philadelphia, PA, USA. ${ }^{2}$ Philadelphia VA Medical Center, Philadelphia, PA, USA. ${ }^{3}$ Regione Emilia-Romagna, Bologna, Italy.

Published: 6 October 2010

doi:10.1186/1472-6963-10-S2-A2

Cite this article as: Louis et al:: Who is most likely to require a higher level of care: predicting risk of hospitalization. BMC Health Services

Research 2010 10(Suppl 2):A2.
Submit your next manuscript to BioMed Central and take full advantage of:

- Convenient online submission

- Thorough peer review

- No space constraints or color figure charges

- Immediate publication on acceptance

- Inclusion in PubMed, CAS, Scopus and Google Scholar

- Research which is freely available for redistribution

Submit your manuscript at www.biomedcentral.com/submit 